Portland State University

PDXScholar

5-6-1976

\title{
Auditory Short-Term Memory Span and Sequence for Five Different Stimulus Types
}

Sandra L. Burford

Portland State University

Follow this and additional works at: https://pdxscholar.library.pdx.edu/open_access_etds

Part of the Speech and Hearing Science Commons

Let us know how access to this document benefits you.

\section{Recommended Citation}

Burford, Sandra L., "Auditory Short-Term Memory Span and Sequence for Five Different Stimulus Types" (1976). Dissertations and Theses. Paper 2585.

https://doi.org/10.15760/etd.2580

This Thesis is brought to you for free and open access. It has been accepted for inclusion in Dissertations and Theses by an authorized administrator of PDXScholar. Please contact us if we can make this document more accessible: pdxscholar@pdx.edu. 
AN ABSTRACT OF THE THESIS OF Sandra L. Burford for the Master of Science in Speech Communication presented May 6, 1976.

Title: Auditory Short-Term Memory Span and Sequence for Five Different Stimulus Types.

APPROVED BY MEMBERS OF THE THESIS COMMITTEE:

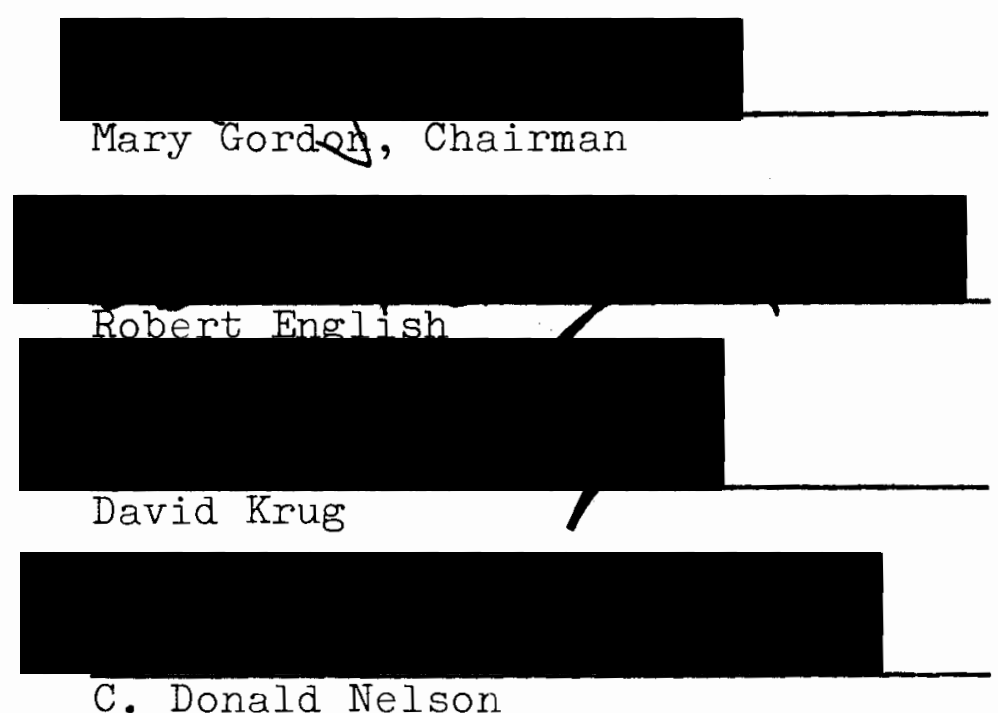

This study investigated the effects of stimulus type on the measurements of short-term auditory memory span and short-term auditory memory for sequence to determine if span and sequence measures were the same within each of five subtests and if span and/or sequence measures varied across all five subtests. A total of forty-five normal second, third, and fourth grade subjects were individually administered the Auditory Memory Test Battery (AMTB) which 
consisted of five tape-recorded tests of recall for digit sequences, unrelated word sequences, related word sequences, nonsense word sequences, and sentences. The subjects responded verbally to the randomly presented subtests. Each subject obtained ten scores: a span score and a sequence score for each of the five subtests.

The results of the study showed the span and sequence scores for the digit task differed significantly, with the span task being easier; however, the scores did not differ significantly for unrelated words, related words, nonsense words, or sentences. Both span and sequence performances were found to vary significantly with the type of stimulus; however, no difference was found in sequence performance between related and unrelated words. Generally, sentence recall was easier than recall of individual words, and recall of nonsense words was most difficult. 


\title{
AUDITORY SHORT-TERM MEMORY SPAN AND SEQUENCE FOR FIVE DIFFERENT STIMULUS TYPES
}

\author{
by
}

SANDRA L. BURFORD

A thesis submitted in partial fulfillment of the requirements for the degree of

MASTER OF SCIENCE

in

SPEECH COMINUN ICATION :

EMPHASIS IN SPEECH PATHOLOGY

Portland State University

1976 
TO THE OFFICE OF GRADUATE STUDIES AND RESEARCH:

The members of the Committee approve the thesis of Sandra I. Burford presented May E, 1976.
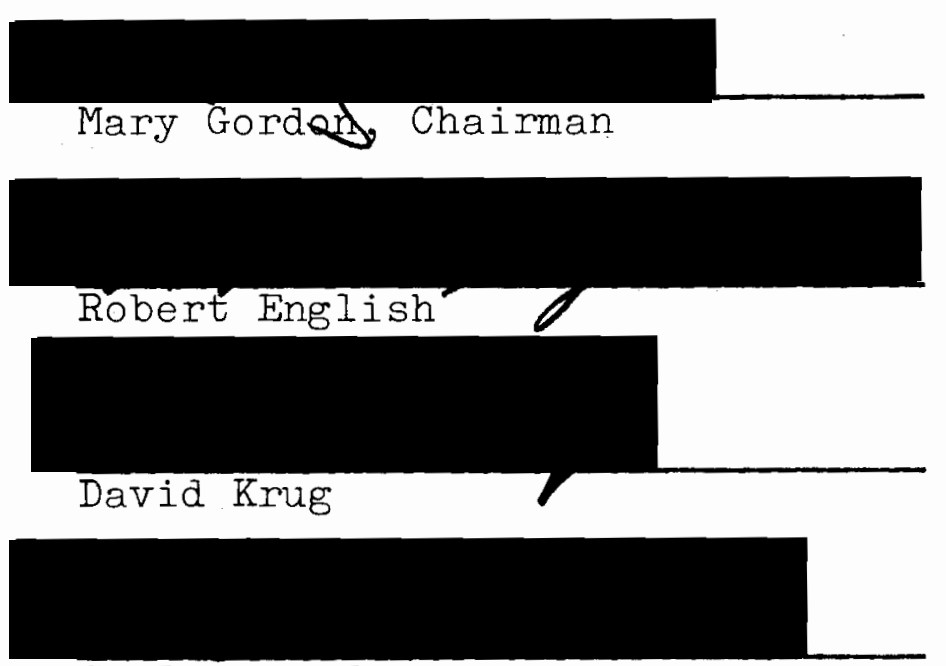

C. Donald Nelson

\section{APPROVED :}

Robert W. Voge Wang, Chaj rman, Department of Speech Communjcation

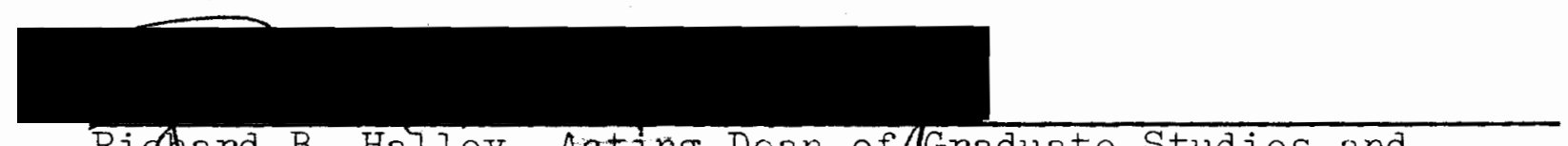

Richard B. Halley, Acting Dean of $/$ Graduate Studies and
Research

May 19, 1976 


\section{ACKNOWLEDGMENTS}

This study could not have been undertaken without the assistance and support of many individuals. My deep appreciation goes, first, to Mary Gordon, my advisor and committee chairman. Her interest and encouragement in this project remain invaluable. Thanks go also to the members of the committee, with special thanks to Dr. R. H. English, who provided the original impetus for the research, and to Dr. C. D. Nelson for his assistance in the test construction. I must express the deep gratitude I have for the many hours given by Dr. Jack Hegrenes. His guidance in the statistical analysis and his critical questioning were helpful beyond measure. Thanks must go also to Stan Nuffer for his technical assistance in the construction of the test tapes.

I wish to express many thanks to the principals, teachers, secretaries, parents, and students of Stephenson and George Smith Elementary Schools. Without their cooperation and patience this study could not have been completed. Thanks go also to Mrs. Candy Piazza for her encouragement in the project, and to Mrs. Barbara Vogelsang for her assistance in preparing and typing the thesis.

Finally, I express once again my deepest appreciation to my family. They have wholeheartedly supported my educational aspirations, no matter the cost in time, money, and 
patience. Not the least of this support has come from my husband, Jim, who has been patient, generous, and understanding throughout my educational program. It is to him I dedicate this work. 
TABLE OF CONTENTS

PAGE

ACKNOWLEDGMENTS

CHAPTER

I INTRODUCTION AND STATEMENT OF PURPOSE $\cdot$. . I I

Introduction ........... I 1

Statement of Purpose . . . . . . 4

II REVIEW OF THE LITERATURE . . . . . . . . 5

Factors Influencing Memory . . . . . 5

Span and Sequence . . . . . . 6

Varied Stimulus Types . . . . . . 8

Conclusions . . . . . . . . 13

III METHODS AND PROCEDURES . . . . . . . 14

Methods . . . . . . . . 14

Subjects

Test Battery

Test Construction

Instrumentation

Procedures . . . . . . . . .

Test Administration

Data Measurement

Data Analysis

IV RESULTS AND DISCUSSION

Results . . . . . . . . 25

Discussion . . . . . . . 30 
$\mathrm{V}$ SUMMARY AND IMPLICATIONS $\cdot \cdot \cdot \cdot \cdot \cdot \cdot \cdot \cdot \cdot \cdot$

Summary . • . • . . . • • • • 35

Implications . . . . . . . . . . 36

Clinical Implications

Research Implications 


\section{IIST OF TABLES}

TABLE

PAGE

I Means, Standard Deviations, and T-Values

for Span and Sequence Scores for Five

Subtests . . . . . . . . . . 26

II Analysis of Variance for Effect of Stimulus

Type on Memory Span for Five Stimulus

Types . . . • • • . • . • • • •

II Analysis of Variance for Effect of Stimulus

Type on Memory for Sequence for Five

Stimulus Types . . . . . . . . •

IV Differences Between Five Subtest Means

for Memory Span and Memory for

Sequence (Duncan's Multiple-Range

Test) . . . . . . . . . . . . 


\section{CHAPTER I}

\section{INTRODUCTION AND STATEMENT OF PURPOSE}

\section{INTRODUCTION}

In order to learn, the human being must be able not only to receive, or sense, incoming stimuli; he must be able also to perceive them. Perception is a highly complex process which involves many component functions, including attention, recognition, discrimination and differentiation of figure-ground (Myklebust 1971a). The function of storage or retention of information (memory) is considered to be linked to perceptual operations (Aaronson 1974).

The learning of language depends upon the process of auditory perception. A cooperative function, auditory memory, also appears to be critical for language development (Johnson and Myklebust 1971). After the acuity to sense the auditory message, the next most basic function is the storage of the stimulus for a long enough duration to permit further perceptual processing. This storage, or retention, is the function of short-term auditory memory. Measures of memory include both immediate recall of a stimulus and delayed recall of a stimulus, since immediate memory differs from delayed memory (Myklebust 1971a). 
Because of the dependence of language comprehension upon the instant recall of auditory messages (Berry 1969), language clinicians are concerned with the measurement of immediate recall of auditory stimuli.

A review of the literature regarding measurement of short-term memory (Fudala 1975) indicates there is a need to divide the concept "short-term memory" into two levels of function. The more basic of the two is the retention of the message, or stimulus, but not in particular serial order. This level, which will be termed "memory span," involves only the retention and recall of the individual items or parts of the stimulus. The second level is the retention of the stimulus items in the particular serial order in which they were presented. This is a higher level of functioning. Serial retention of items for immediate recall involves retention of the temporal positioning of the stimulus items as well as retention of the items themselves. This higher function will be termed "memory for sequence." A distinction is apparent between the two measures of memory (span and sequence) when diagnosing learning disabilities and dyslexia in children. Empirical evidence reveals these children often show a difference between memory span and memory for sequence abilities (McCarthy and McCarthy 1969, Johnson and Myklebust 1971). The importance of this distinction cannot be determined without some measure of the span and sequence performances of normal children. 
Tests of auditory short-term memory span and memory for sequence are often used in test batteries to measure language and intellectual capacities. Many types of stimuli, such as digits, nonsense words, and sentences, are used in measuring auditory memory. There is some question reflected in current research that tests of memory span and memory for sequence may be used interchangeably (Turaids, Wepman, and Morency 1972, Fudala 1975). A question also exists regarding the relative efficacy of measurements of memory which use different types of stimuli (Berry 1969). Some research has explored auditory memory span and memory for sequence through the use of both span and sequence measures (Aten and Davis 1968, Zigmond 1969, Turaids, Wepman, and Morency 1972, Fudala 1975). Some research has also explored auditory memory through the use of more than one type of auditory stimulus (Hayes 1952, Aten and Davis 1968, Monsees 1968, McCarthy and Olson 1969, Zigmond 1969, Turaids, Wepman, and Morency 1972, Liasky, Jay, and Hanz 1973). Considering the already mentioned need to compare measures of memory span with measures of memory for sequence in normal children, and the need for a comprehensive battery of auditory memory tests (Myklebust 1971b), there appears to be a need for research which systematically combines these two attributes. This researcher did not find the studies which have considered these two attributes (Aten and Davis 1968, Zigmond 1969, Turaids, Wepman, and Morency 1972 ) either comprehensive or systematic in reporting 
control of variables. The present study sought to use a carefully controlled battery of auditory memory tests to measure memory span and memory for sequence in normal children.

\section{STATEMENT OF PURPOSE}

This study was designed to investigate the effect of stimulus type on the normal child's memory span and memory for sequence for auditory stimuli. The five stimulus types included: (1) digits, (2) unrelated words, (3) related words, (4) sentences, and (5) nonsense words. The investigation sought to answer three questions:

1. Will the span measures differ from the sequence measures within each stimulus type?

2. Will the span measures differ between the stimulus types?

3. Will the sequence measures differ between the stimulus types? 


\section{CHAPTER II}

\section{REVIEW OF THE IITERATURE}

\section{FACTORS INFLUENCING MEMORY}

The function of memory, and likewise the measurement of memory, appears to be influenced by several factors. These factors work upon the individual during learning, especially learning of language and verbal material. Among the factors affecting retention of a stimulus sequence are: (1) the length of the stimulus, (2) the type of stimulus, (3) the familiarity of the stimulus, (4) the position of the elements in the stimulus series, (5) syntax and grammatical structure, (6) rate of presentation, and (7) meaningfulness of the stimulus (Aten 1972, Chalfant and Scheffelin 1969).

Many of these factors may be manipulated in experimental measurement of memory abilities, including ( 1 ) length of stimulus, as measured by memory span, (2) position of elements in the stimulus series, as measured by memory for sequence, and (3) type of stimulus. These three parameters of measurement have been the subject of research in auditory memory. The following review presents some research which has dealt most directly with these parameters. 


\section{SPAN AND SEQUENCE}

Aten and Davis (1968) tested the auditory sequence perception of normal children and children with central nervous system dysfunction. The authors used three nonverbal and seven verbal auditory perception tasks. The seven verbal tasks involved varied stimulus types (discussed later) to measure the retention and recall of the stimulus. Six of the seven verbal tasks required the exact serial reproduction of the stimuli. The paragraph recall task, however, made no provision for evaluation of errors of serial positioning. Aten and Davis suggested such qualitative differences should be evaluated, since an absolute number of words recalled did not necessarily reflect a subject's pattern of response in this case. The children with minimal cerebral dysfunction (MCD) tended to reverse word orders and made other qualitative errors which may have discriminated them from the normal subjects, given a more sensitive evaluative tool.

In her study of the auditory, visual, and intersensory functions in normal and dyslexic children Zigmond (1969) found results similar to those of Aten and Davis. She measured auditory memory span and sequence through five different types of stimuli. Zigmond found differences between span and sequence scores for both groups.

A study showing results differing from those already discussed was conducted by Turaids, Wepman, and Morency (1972). 
These researchers standardized a perceptual test battery on 1,008 normal children, including three measures of auditory memory in their battery. Two of the measures, memory span for unrelated nouns and digit sequencing, tested span and sequence, respectively. The researchers did not find a significant difference between the span and sequence scores, and therefore concluded ". . . the two tests may be used almost interchangeably." The present researcher found three discrepancies which would appear to limit their conclusion: (1) the range of stimulus items from two to six was reported for memory span while the range of stimulus items was not reported for digit sequencing, (2) the memory span items were monosyllabic words, while the number of syllables in the digit sequencing task was not reported, and (3) the span and sequence measures were compared for different stimulus types. The research done by Fudala (1975) appears to support the findings of Aten and Davis (1968) that in certain groups span and sequence measures vary. Fudala reported the results of a study measuring auditory span and sequence ability in a hearing impaired population, using a visual-pointing response to an auditory stimulus. She found span and sequence measures discriminated conductive from sensorineural losses. Children with conductive losses showed no difference between the two scores, while children with sensorineural losses often obtained higher span than sequence scores. Fudala felt this discrepancy might indicate a dysfunction in 
higher perceptual processing in some children with sensorineural losses. Although her research appeared to investigate intersensory abilities, she concluded span and sequence must be measured separately in tests of auditory memory.

\section{VARIED STIMULUS TYPES}

The most common types of stimuli used in measurements of auditory memory span and memory for sequence have been digits, unrelated words, sentences, and nonsense syllables (Aten 1972, Zigmond 1969). Several studies have involved the use of different types of stimuli.

The earliest study reported in this review is a study by Hayes (1952), which used digits, letters, and words in five separate information-graded tests of memory span. Hayes tested the hypothesis of Miller (Hayes 1952) that memory capacity is related to the redundancy of the stimulus items. The results of this study showed recall varied only slightly with large variations in redundancy. Hayes concluded test designs need not control for information, and inferred variations in recall might occur with manipulation of other variables, such as linguistic rules and familiarity of stimulus material.

Two familiar types of stimuli, digits and words, were used in the carefully designed study by McCarthy and Olson (1964, as reported by Lamb, 1969). The authors investigated the validity of the Auditory-Vocal Sequencing subtest of the 
Illinois Test of Psycholinguistic Abilities (ITPA) (McCarthy and Kirk 1963) by testing a group matching the original standardization group. Their instrument was specifically designed to match the test of random numbers, using random words. Their results showed no significant differences between the results from testing digits and from testing words. McCarthy and Olson concluded the digit sequence test is a valid test of memory. The implications of their data for other tests of memory however, are not clear, since they did not report what type of words they used with respect to semantic relatedness, number of syllables, or other linguistic constraints.

Monsees (1968) manipulated the two variables of linguistic rules and familiarity which had been mentioned earlier by Hayes (1952). Monsees tested auditory sequencing ability in normal and ELP (Expressive Language Problems) subjects by administering phonemic repetition tests of familiar and unfamiliar words, and nonwords to both groups. Her results found the normal group made more errors on words of both types than on nonwords, possibly because of inefficient recall strategies used for the words. Monsees hypothesized the normal subjects had better success with the nonwords because they did not employ strategies, and the task became straight repetition. The ELP subjects showed different results. They had most success with easy, familiar words, and more difficulty with nonwords and unfamiliar words. 
These latter became straight repetition tasks, and the subjects' apparently reduced memory capacity failed them. Linguistic rules were also considered in the research by Turaids, Wepman, and Morency (1972), mentioned earlier. Their linguistic units were different from those used by Monsees, since they included digits, unrelated words, and sentences. The authors used only normal subjects in their test standardization study. As previously discussed, the results showed no difference between the unrelated word test and the digit test. These two tests do not appear to have been carefully controlled. (See the three discrepancies discussed on page 7.) This researcher found the test of sentences to be more carefully controlled; however, one does not know the significance of the discrepancy between the sentence test results and the results of the other two tests. The authors attributed the discrepancy to syntactic and intonational constraints in the sentences which were absent in the tests of words and digits. This conclusion appears appropriate, but would have been stronger if greater control of variables had been reported for the three tests. Aten and Davis (1968), also previously discussed, studied the differences of their two subject groups on ten measures of sequencing ability. The seven verbal types of stimuli included nonsense syllables, digits, noun sequences, multisyllabic words, scrambled sentences, paragraph recall, and oral sequences of syllables similar to those used in 
diadochokinetic measurements. All except the noun sequencing task required a verbal response; a motor response was used for the latter.

The authors found several of the tests discriminated between the two groups. These tests were serial nouns, multisyllabic words, backward digits, and scrambled sentences. Only a few comparisons between the tests were made for either group. The digits-forward and digits-backward tests appeared to measure different abilities in both groups. The nonsense syllables, digits-forward, and paragraph recall were considered similar in the type and level of skills measured for the MCD group. The authors suggested, however, the rate of presentation of the digits (one per second) may not have been as sensitive as the rate (two per second) used in the ITPA (McCarthy and Kirk 1963). The authors criticized any objective comparison of the serial noun and serial digit tests, since a different type of response (motor) was required for the noun task from that of the digit tasks (oral). Other criticisms were made of the tests of nonsense syllables and paragraph recall, and Aten and Davis suggested further research is necessary using more well-designed tests.

These authors came quite close to an objective comparison of several measures of auditory memory. The methodological criticisms they discussed, however, appear to have limited an objective comparison. 
Zigmond (1969) also appeared to measure several types of stimuli. She included tests of nonsense words, digits, words, sentences, and rhythmic sequences (taps). She did not differentiate, however, between the tests of auditory memory, and from the limited information available regarding the stimulus items, one may not objectively compare them with each other.

The two variables considered by Monsees (1968), linguistic rules and familiarity, were also manipulated by Lasky, Jay, and Hanz (1973) in a study of delayed recall of auditory sequences. The subjects were normal and "learning disabled" children. The results of their study, in contrast to Monsees' results, showed better recall for meaningful linguistic (unrelated words) stimuli than for nonmeaningful linguistic (nonsense syllables) stimuli. The stimulus variables in their study were more carefully controlled than in any other study in the present review, making comparison between types of stimuli significant. Generalizability of these delayed-recall data to tasks of immediate recall however, is difficult, considering the inherent difference between immediate and delayed memory (Myklebust 1971a). The careful control utilized in the research of Lasky, Jay, and Hanz (1973) is needed in research involving immediate auditory recall. 
IV. CONCLUS IONS

A review of the literature appeared to show a need to evaluate memory span and memory for sequence separately in testing auditory memory, since these two measures may discriminate between either normal and abnormal subjects, or two groups of abnormal subjects. One study found span and sequence measures did not differ in normal subjects; however, methodological weaknesses may limit the strength of this result.

Only one study reviewed carefully controlled the variations between types of stimuli. This study utilized a delayed-recall response, which is not generalizable to immediate-recall research. It may be concluded both measures of span and sequence, and measures utilizing different types of stimuli in tests of immediate auditory memory must be carefully controlled to compare them objectively. 


\section{CHAPTER III \\ METHODS AND PROCEDURES}

I. METHODS

\section{Subjects}

Subjects for this study were selected from the George Smith and Stephenson Elementary Schools, Portland, Oregon. Forty-five subjects, fifteen from each of the second, third, and fourth grade levels, were randomly selected from those children meeting the following criteria:

1. Received permission from parent or guardian to participate in the study. (See Permission Form, Appendix A.)

2. Received no remedial speech, language, or reading instruction, as reported by the parents. (See Permission Form, Appendix A.)

3. Passed the speech and language screening administered by the school speech pathologist, as determined by consulting the speech pathologist.

4. Displayed no known physical handicap, as reported by the classroom teacher.

5. Passed the audiometric screening administered by this examiner by responding positively to two of three presentations at $25 \mathrm{~dB}$ for each of the tones $500 \mathrm{~Hz}$, $1000 \mathrm{~Hz}, 2000 \mathrm{~Hz}$, and $4000 \mathrm{~Hz}$ bilaterally. 
Subjects were selected with no preference to sex. The sixteen males and twenty-nine females ranged in age from 7 years, 6 months to 11 years, 4 months, with a mean age of 8 years, 10 months. The socioeconomic level of the two schools from which the subjects were selected was determined to be upper-middle class (Hunt 1976).

\section{Test Battery}

The Auditory Memory Test Battery (AMTB) consisted of the following subtests:

1. Digit sequencing (adapted from the Auditory-Vocal Sequencing subtest of the Illinois Test of Psycholinguistic Abilities (ITPA) (Kirk, McCarthy, and Kirk 1968).

2. Unrelated word sequencing (adapted from the Auditory Attention Span for Unrelated Words subtest of the Detroit Tests of Learning Aptitude (Baker and Leland 1959).

3. Sentence sequencing (sentences comprised of monosyllabic words which were devised by this examiner and C. D. Nelson, Ph.D., Speech Pathologist, University of Oregon Health Sciences Center, Portland, Oregon).

4. Related word sequencing (lists of semantically related monosyllabic words devised by this examiner and Dr. Nelson).

5. Nonsense word sequencing (lists of monosyllabic nonsense words devised by this examiner). 
Each subtest of the AMTB was comprised of the following: (1) two sample items, each two monosyllables in length, and (2) 14 test items ranging in length from two to eight monosyllables. Subtests which were adapted from standard instruments (digit sequencing and unrelated word sequencing) and which contained polysyllabic words were modified to contain only monosyllables. For example, all "seven" words on the digit sequencing task were replaced with randomly selected monosyllabic digits. The AMTB items are presented in a sample Response Form shown in Appendix B.

\section{Test Construction}

The five subtests of the AMTB were tape-recorded for later presentation to the subjects. The examiner's own voice was used to record each subtest. Sample and test items were first recorded utilizing a reel-to-reel tape recorder according the following procedures:

1. Serial word items were presented at the rate of two words per second with falling vocal inflection used at the end of the sequence. This procedure was adapted from the ITPA (Kirk, McCarthy, and Kirk 1968).

2. Sentence items were presented at approximately two words per second with normal inflection used.

3. Two sample items were presented at the beginning of each subtest. This procedure was adapted from the ITPA (Kirk, McCarthy, and Kirk 1968). 
4. Approximately 10 seconds of silence were recorded immediately following each item during which the subject was expected to respond.

5. Two trials and response periods were recorded for each item. This procedure was adapted from the IMPA (Kirk, McCarthy, and Kirk 1968).

Each subtest was then duplicated from the reel tape onto an individual cassette tape.

The five subtests on cassette tapes were judged for intelligibility by two certified speech pathologists prior to administration of the AMTB to the subjects. The speech pathologists listened to the recorded items and wrote each stimulus word as they heard it. Agreement between the two transcripts of the speech pathologists was 100 per cent for digit sequencing, sentence sequencing, and related word sequencing. Agreement on the unrelated word sequencing was 94.5 per cent, and agreement on the nonsense word sequencing was 93 per cent. Words on which the two speech pathologists disagreed were played for two other trained listeners (see Seven Word Discrimination List, Appendix C), and the listeners independently chose the transcription with which they agreed for each word. Agreement between these two Iisteners was 100 per cent for the seven words. The transcripts of the speech pathologists, and the judgments of the other trained listeners (on the seven words on which the 
speech pathologists disagreed) were used in devising the response form. (See Response Form, Appendix B.)

The order of presentation of the subtests was determined through randomization procedures. The subtests were assigned numbers and randomly ordered. These random "sets" were assigned to numbers 1 through 45 which represented the subjects to be tested. (See Test Order List, Appendix D.)

Instrumentation

A Sony Condenser Microphone Model C-37A and a Sony Stereo Tapecorder Model TC 777-2 (half-track) were used for the original recording of the subtests onto reel tapes. The subtests were recorded at 7-1/2 ips using Ampex 406 Mastering Tape. They were then duplicated using TDK C-60Y cassette tapes at $1-7 / 8$ ips with a Telex Series 235 CS-1 Reel to Cassette Duplicating System.

Ambient room noise in the testing environments at the two schools, and the loudness of tape presentation to the subjects were measured with the General Radio, USA Model 1565-B Sound I Level Meter.

The audiometric screening of the subjects was completed using a Maico portable audiometer Model MA 16.

The cassette tape recorder used for administration of the AMTB to all subjects was the Sony Model TC-95A (twotrack mono). For further specifications on the instruments used in the study, see Instrumentation Specifications in Appendix E. 


\section{PROCEDURES}

\section{Test Administration}

Audiometric screening of all subjects who met criteria 1, 2, 3, and 4 (see Subjects, page 14) was completed prior to the administration of the AMTB. Those subjects passing the audiometric screening were administered the AMTB.

The AMTB was administered individually to each of the forty-five subjects. The examiner escorted each subject from his/her classroom to the testing room, engaging the subject in casual conversation during the interval to gain rapport. The AMTB was administered in a relatively quiet room in the students' schools. The average level of ambient room noise in each of the two testing environments was found to be $40 \mathrm{~dB}$ (A scale) and $50 \mathrm{~dB}$ (C scale) as measured on three separate occasions. During test administration each subject sat facing the examiner across a small table on which were placed the cassette tape recorder and the subtest tapes. Recording forms, and lists of subjects and subtest presentation order were placed on the shelf under the examiner's side of the table.

Before beginning the test administration, the examiner noted the subject's name and "set" order number on a recording form, crossing the corresponding "subject number" and "set" order code off the Test Order List (Appendix D). In order to shorten administration time, the examiner transferred other pertinent information regarding subjects from 
a master list to individual response forms during the scoring time. The examiner next marked order numbers in the square by each subtest title on the response form. (See Response Form, Appendix B.)

The examiner gave the following verbal instructions to each subject:

I am going to play five tapes for you. On each tape there will be a lady saying some words. Please listen very carefully to what the lady says. Whenever she stops, you say the same thing she just said. The lady will say the words two times. She will say them, then you say them; she will say the words again, then you say them again. Some of the things she will say will be harder to remember than others, and some won't make sense. Just listen carefully and do the best you can to say exactly what she says.

The examiner then played the two trials each of the two sample items on the first tape. If a subject failed to respond to at least the second trial of the first sample item, the examiner stopped the tape, instructed again, and played the second sample item. The tape was not stopped again unless the subject failed two consecutive test items on both trials, at which time the subtest was discontinued. The examiner gave general positive reinforcement such as "you're doing fine" after each subtest was administered, and gave the instructions, "Listen carefully; the next tape will be different from the last one."

The above described procedure was used for the administration of the remaining four subtests. In addition to the inter-subtest instructions, the following instruction 
was given prior to the administration of the nonsense word subtest: "These words won't make sense."

The administration of the AMTB to each subject proceeded smoothly, and had an average duration of 30 minutes. The average loudness level of the tapes was approximately $61 \mathrm{~dB}$ ( $\mathrm{A}$ scale), and approximately $62 \mathrm{~dB}$ (C scale). Brief physical or noise interruptions occurred during the administration of the AMTB to four subjects. At those times the examiner stopped the tape and started it again when the interruption had subsided. These interruptions did not noticeably affect the responses of the four subjects.

\section{Data Measurement}

Responses to each subtest were recorded by the examiner during its administration. All responses, including those to the sample items, were recorded according to the following procedure:

1. A correct response on either trial of an item was recorded by placing a check $(\checkmark)$ beside the item on the response form (see Appendix B). Criteria for correctness were as follows: (a) all words within an item had to be in correct serial order, (b) all words in responses to digit, related word, and sentence items had to match the stimulus words identically, and (c) all words in responses to unrelated word and nonsense word items could deviate by one distinctive feature (Drexler 1974) for one consonant per word. An 
example of a deviation of one distinctive feature is the response "card" to the stimulus "cart." Judgments of deviation were made according to the system outlined in the Distinctive Feature Grids (Appendix F). This system was chosen over a linguistic categorization system because the categories used are familiar to speech pathologists (Drexler 1974).

2. An incorrect response on either trial of an item was recorded by noting the error directly below the stimulus on the response form. Digit responses were noted as digits, word responses as words, and nonsense word responses as phonetic symbols using the broad notation of the International Phonetic Alphabet. All unintelligible responses were noted as such on the response form.

3. If the response to the first trial on any item was correct, the second trial on that item was administered, but not scored.

All subtests were scored after the administration of the AMTB to the forty-five subjects was completed. Items were scored for both span (all words in an item recalled) and sequence (all words in correct serial position). Scoring followed the procedure below:

1. Responses completely correct (see criteria for correctness, Data Measurement, page 21) on the first trial earned two points each for span and sequence. 
2. Responses completely correct on the second trial earned one point each for span and sequence.

3. Responses including all words in an item but not in correct serial order on the first trial earned two points for span and none for sequence.

4. Responses including all words in an item but not in correct serial order on the second trial earned one point for span and none for sequence.

For any responses to two trials of an item, the subject was credited with the greater number of points earned for span. If, for example, the subject recalled all of the words in an item on the first trial, but erred in the serial order, then went on to respond correctly on the second trial, the subject would earn two points for span and one point for sequence on that item.

A total span score was derived for each of the five subtests for each subject by summing the span scores within the subtest. A total sequence score was derived similarly for the sequence scores within each subtest. Each subject thus obtained ten total scores: a span score and a sequence score for each of the five subtests. 
Data Analysis

A t-statistic using the following formula

$$
s^{2}=\frac{n \sum x^{2}-\left(\sum x\right)^{2}}{n(n-1)}
$$

with $\mathrm{T}=\frac{\overline{\mathrm{x}}_{1}-\overline{\mathrm{x}}_{2}}{\mathrm{~s}_{\mathrm{p}} \frac{1}{\mathrm{n}_{1}}+\frac{1}{\mathrm{n}_{2}}}$ where $\mathrm{s}_{\mathrm{p}}=\sqrt{\frac{\mathrm{s}_{1}^{2}\left(\mathrm{n}_{1}-1\right)+\mathrm{s}_{2}^{2}\left(\mathrm{n}_{2}-1\right)}{\mathrm{n}_{1}+\mathrm{n}_{2}-2}}$

was used to measure significant differences in the data to determine if the span measures and sequence measures were the same within each stimulus type.

A One-Way Analysis of Variance (Hays 1973) was used to determine if the span measures varied with the stimulus type. A One-Way Analysis of Variance was used to determine if the sequence measures varied with the stimulus type. 


\section{CHAPTER IV \\ RESULTS AND DISCUSSION}

I. RESULTS

This study investigated the effects of five stimulus types on the short-term auditory memory span and auditory memory for sequence of forty-five normal second, third, and fourth grade students. The study sought to answer the three questions posed at the outset of this investigation. The questions and the results of the investigation follow.

The first experimental question was: will the span measure differ from the sequence measure within each stimulus type? For example, will the span score for digits be the same as the sequence score for digits? A two-tailed t test for related measures was used to determine if significant differences occurred between the mean auditory memory span score and the mean auditory memory for sequence score for each stimulus type. Table I displays the results. No statistically significant difference was found at the .05 level of confidence between the span measures and sequence measures for four of the subtests: unrelated words, related words, nonsense words, and sentences. The difference between span and sequence measures for the digit 
sequencing subtest was significant beyond the .05 level of confidence. The recall of digits without regard to order (span) appeared to be easier than recalling the digits in order (sequence). Thus, sequencing performance was not shown to be significantly more difficult than span performance for any stimulus type except digits.

\section{TABLE I}

MEANS, STANDARD DEVIATIONS, AND T-VALUES FOR

SPAN AND SEQUENCE SCORES FOR FIVE SUBTESTS

\begin{tabular}{|c|c|c|c|}
\hline Subtest & Mean Scores & $\mathrm{SD}$ & $t$-Value \\
\hline Digit Sequencing & & & $1.84^{*}$ \\
\hline $\begin{array}{l}\text { Span } \\
\text { Sequence }\end{array}$ & $\begin{array}{l}19.47 \\
17.48\end{array}$ & $\begin{array}{l}3.25 \\
3.03\end{array}$ & \\
\hline Unrelated Word Sequencing & & & .95 \\
\hline $\begin{array}{l}\text { Span } \\
\text { Sequence }\end{array}$ & $\begin{array}{l}12.89 \\
12.42\end{array}$ & $\begin{array}{l}3.07 \\
2.37\end{array}$ & \\
\hline Related Word Sequencing & & & 1.32 \\
\hline $\begin{array}{l}\text { Span } \\
\text { Sequence }\end{array}$ & $\begin{array}{l}14.73 \\
13.98\end{array}$ & $\begin{array}{l}2.81 \\
2.48\end{array}$ & \\
\hline Sentence Sequencing & & & .04 \\
\hline $\begin{array}{l}\text { Span } \\
\text { Sequence }\end{array}$ & $\begin{array}{l}27.67 \\
27.67\end{array}$ & $\begin{array}{l}.76 \\
.76\end{array}$ & \\
\hline Nonsense Word Sequencing & & & .07 \\
\hline $\begin{array}{l}\text { Span } \\
\text { Sequence }\end{array}$ & $\begin{array}{l}7 \cdot 56 \\
7 \cdot 51\end{array}$ & $\begin{array}{l}2.73 \\
2.69\end{array}$ & \\
\hline
\end{tabular}


The second experimental question was: will the span measures differ between the stimulus types? Table II displays the results. An analysis of variance for the five stimulus types showed a significant difference beyond the .001 level of confidence between the span measures. Therefore, the stimulus type did affect performance on memory span tasks.

TABLE II

ANALYSIS OF VARIANCE FOR EFFECT OF STIMULUS TYPE ON MEMORY SPAN FOR FIVE STIMULUS TYPES

\begin{tabular}{lrrrrr}
\hline \hline Source & SS & df & ms & F & p \\
\hline Within Groups & 10334 & 4 & 2584 & 369.14 & $<.001$ \\
Between Groups & 1541 & 220 & 7.00 & -- & -- \\
Total & 11875 & 224 & -- & -- & -- \\
\hline
\end{tabular}

The third experimental question was: will the sequence measures differ between the stimulus types? Table III displays the results. An analysis of variance for the sequence measures showed a significant difference beyond the .001 level of confidence between the five stimulus types. The stimulus type thus affected the performance on memory for sequence tasks. 
TABLE III

ANALYSIS OF VARIANCE FOR EFFECT OF STIMULUS TYPE ON MEMORY FOR SEQUENCE FOR FIVE ST IMULUS TYPES

\begin{tabular}{crrrrr}
\hline \hline Source & SS & df & ms & F & p \\
\hline Within Groups & 10278 & 4 & 2569 & 301.88 & $<.001$ \\
Between Groups & 1872 & 220 & 8.51 & -- & -- \\
Total & 12150 & 224 & -- & -- & -- \\
\hline
\end{tabular}

The analyses of variance showed at least two of the five span scores differed, and at least two of the five sequence scores differed. To find the specific source(s) of variation between the five subtests for both span and sequence, the data were analyzed using Duncan's MultipleRange Test. The mean span scores for the five stimulus types were ranked from smallest to largest. The mean sequence scores were similarly ranked. Comparisons were made between adjacent span means and between adjacent sequence means to determine if significant differences existed between the least differing pairs of means. The results are displayed in Table IV.

Significant differences were found between the adjacent paired means for memory span. The smallest significant difference between the pairs was larger than the minimum difference allowed for significance across five means; therefore, a comparison between any combined pair of means would show a significant difference. 
For the sequence means, only one pair of adjacent means did not show a significant difference. No difference was found between the mean sequence scores for unrelated word sequencing and related word sequencing. All other paired adjacent means were found to differ significantly.

This analysis of the subtest means found each of the mean span scores for the five subtests a source of variation. When analyzed in pairs, each differed significantly from the other span means. A source of variation between the sequence scores was found in each mean, when analyzed in pairs, with the exception of the pair unrelated words and related words. These means did not differ significantly from each other. 
TABLE IV

DIFFERENCES BETWEEN FIVE SUBTEST MEANS FOR MEMORY SPAN AND MEMORY FOR SEQUENCE (DUNCAN'S MULTIPLE-RANGE TEST)

\begin{tabular}{|c|c|c|c|c|c|}
\hline SPAN & I. & II. & III. & IV. & V. \\
\hline I. Nonsense Words & - & & & & \\
\hline II. Unrelated Words & $5.33^{*}$ & - & & & \\
\hline III. Related Words & $7.17^{*}$ & $1.84^{*}$ & - & & \\
\hline IV. Digits & $11.91^{*}$ & $6.58^{*}$ & $4.74 *$ & - & \\
\hline V. Sentences & $20.11^{*}$ & $14.78^{*}$ & $12.94^{*}$ & $8.20^{*}$ & - \\
\hline${ }^{*} \mathrm{p}<.05$ & $=1.48$ & $\mathrm{R}_{5}=$ & 1.62 & & \\
\hline SEQUENCE & I. & II. & III. & IV. & V. \\
\hline I. Nonsense Words & - & & & & \\
\hline II. Unrelated Words & $4.86^{*}$ & - & & & \\
\hline III. Related Words & $6.47^{*}$ & 1.52 & - & & \\
\hline IV. Digits & $10.33^{*}$ & $5.42 *$ & $3.86^{*}$ & - & \\
\hline V. Sentences & $20.16^{*}$ & $15.25 *$ & $13.69 *$ & $9.83^{*}$ & - \\
\hline
\end{tabular}

\section{DISCUSSION}

The results of the first question posed in this study. offer limited support to the findings of Zigmond (1969) in her study of the performance of "normal" and dyslexic subjects on five recall tests, including digit recall. When 
tested by a traditional digit recall test, normal and dyslexic subjects showed a discrepancy between the number of items recalled and the number of items recalled in correct serial order. The normal subjects in the present study also showed a greater overall memory span than memory for sequence. Additionally, they tended to make serial confusions on "relatively easy" digit items, a tendency which was not shown to the same degree on the other subtests. A large percentage of the errors of this type can be attributed to generalizations of place (from previous items) or of doubled digits (within the item) (Neisser 1966). An error of the former type would be a response substituting a digit on one item with the digit in the same serial position from the previous item. For example, given the stimulus 4-2-1 with the previous item being 6-9-5, the subject might substitute the 9 for the 2, giving the response 4-9-1. This would be a generalization of place. An error of doubled digits could occur if the subject either doubled the wrong digit, or changed the serial positions of the repeated digits. Examples of these are, respectively: given the stimulus 4-2-2-9, the subject might respond with 4-2-9-9, or with 4-2-9-2.

The comparison of span and sequence measures in each of the four subtests unrelated words, related words, nonsense words, and sentences does not support the hypothesis in the literature that memory span and memory for sequence are different in normal children. Except for the digit 
sequencing subtest, the results strongly support the phenomenon that normal children remember in sequence approximately the same number of words they remember without regard to order. This implies, at least in the normal child, sequence information may assist in the overall retention (memory span) for auditory stimuli, such as in a "slot" theory of memory (Neisser 1966). A "slot" theory holds memory is composed of serial positions or reference points to which a person assigns the items in a sequence. According to a "slot" theory, a person is likely to retain the "order" information about a given item although forgetting other intervening items. The generalization errors made on the digit subtest of the present study are consistent with the "slot" theory of memory.

The results of the second and third questions posed in the present study do not support the findings of Turaids, Wepman, and Morency (1972) which showed no difference between digit recall and unrelated word recall. They compared tests of sequencing and span, respectively, and their results may be explained by the previously discussed difference between memory span and memory for sequence on the digit subtest. These authors might have shown a difference between the performances with the two stimulus types had they compared span with span, or sequence with sequence. McCarthy and Olson (1969) used two sequence measures to compare digit recall with word recall, and found no 
difference between the two. The results of the present study do not support their findings, since in the present study digit recall differed from word recall. McCarthy and Olson did not report the number of syllables used for either. stimulus type, while the present investigator used monosyllabic stimuli for both digit and word measures. Differences in syllabication between the two studies may account for the differing results.

A comparison between the mean memory span scores or the mean memory for sequence scores shows words in sentences the easiest items to recall. These results support the findings of Turaids, Wepman, and Morency (1972) who compared recall of digits, unrelated words, and sentences. Their explanation for the discrepancy between sentence recall and recall of other stimuli appears appropriate to the results of this study. There may have been syntactic and intonational constraints in the sentences which were absent in the other stimulus items. These linguistic constraints may account for the differences between these tests.

The concept of linguistic constraints alone does not appear, however, to explain the comparisons between the subtests related words and unrelated words. Although the mean memory span scores for these two types showed significant differences, no difference was shown between the two mean memory for sequence scores. A semantic-relatedness rule, which may differentiate between the performances on span, 
does not appear to apply to sequence performance. There appears to be a relatively greater number of sequence errors on the related word subtest than on the unrelated word subtest. Gradations of information, such as make little difference in memory span (Hayes 1952), may interact with serial position to affect memory for sequence. Possibly the redundancy of the related words allowed for greater confusion between the serial positions. The words may have lacked the semantic distinctiveness which could assist in the "marking" of serial positions.

The performances on the nonsense word subtest show the effect of semantic rules. These data support the delayed-recall findings of Lasky; Jay, and Hanz (1973), which indicate meaningful stimuli are more easily recalled than nonmeaningful stimuli. The variable of familiarity also may have affected the performance in the present study, since the nonsense words were novel to the subjects.

In conclusion, there appears to be no need to discriminate between span and sequence scores for normal children within any but digit recall tests. Generally, span and sequence performances vary with the type of stimulus, with the exception of sequence performance on related and unrelated word tests, which appear to be similar. For both span and sequence measures, sentence recall tasks are easier than individual word stimuli, and nonsense monosyllable words is the most difficult task. 


\section{CHAPTER V}

\section{SUMMARY AND IMPLICATIONS}

\section{SUMMARY}

This study investigated the effects of stimulus type on the measurements of short-term auditory memory span and short-term auditory memory for sequence to determine if span and sequence measures were the same within each of five subtests and if span and/or sequence measures varied across all five subtests. A total of forty-five normal second, third, and fourth grade subjects were individually administered the Auditory Memory Test Battery (AMTB) which consisted of five tape-recorded tests of recall for digit sequences, unrelated word sequences, related word sequences, ronsense word sequences, and sentences. The subjects responded verbally to the randomly presented subtests. Each subject obtained ten scores: a span score and a sequence score for each of the five subtests.

The results of the study showed the span and sequence scores for the digit task differed significantly, with the span task being easier; however, the scores did not differ significantly for unrelated words, related words, nonsense words, or sentences. Both span and sequence performance 
were found to vary significantly with the type of stimulus; however, no difference was found in sequence performance between related and unrelated words. Generally, sentence recall was easier than recall of individual words, and recall of nonsense words was most difficult.

\section{IMPLICATIONS}

\section{Clinical Implications}

The results of this study imply generalizations should not be made about an individual's auditory short-term memory on the basis of one type of test. Ability varies with the type of stimulus in the normal child, and generalizations from one type to another do not appear to be warranted. Auditory memory span and auditory memory for sequence scores appear to be similar within several stimulus types for normal children; however, this does not imply memory should be tested by only span or sequence measures. Both of these measures should be included in a battery of auditory memory tests, since a difference between the two scores appears to be a significant diagnostic factor. Further, at this time tests which compare span and sequence measures should not use digit stimuli. Normal children appear to perform less well on the sequence task than on the span task; therefore, a difference between the measures may not discriminate normal from perceptually limited children. The trends revealed in this study may facilitate the diagnosis of perceptually defective children. Since norms 
were not established for the AMTB, one may not compare absolute scores earned on the subtests with the present results when using the AMTB in diagnosis. One may, however, measure relative differences between span and sequence scores or between various subtests. Such an informal analysis might indicate a perceptual defect in the child being evaluated.

Research Implications

A need arose from this investigation to study the factors involved in the recall of sentences and recall of nonsense words. Research which compares recall of scrambled sentences or "order-approximations" to sentences with other types of memory tests may prove helpful in finding the "memory" component of sentence recall. Research varying the phonemic complexity of nonsense words, and research involving a "pre-learned" vocabulary of nonsense words used in a memory task may prove helpful in controlling the "familiarity" of the stimulus.

There appears to be a need to investigate further the difference between span and sequence measures for digit-type memory tests. Control of such factors as double digits may be indicated. Research is also needed which compares the one per second rate of presentation used by Aten and Davis (1968), with the two per second rate used by the ITPA (Kirk, McCarthy, and Kirk 1968). Rate of presentation should be measured within word and sentence tasks as well as digit 
tasks, and for language and learning disabled subjects as well as normal subjects.

Further memory research is needed involving stimulus types similar to those used in the present study, but using differing response modes, such as writing the word, or using other visual symbols. A battery of such tests would appear to evaluate auditory-motor or auditory-visual integration as well as auditory memory.

Finally, there appears an overwhelming need for a memory test battery, such as the AMTB, to be standardized. Memory testing, as part of a battery of perceptual tests, appears a promising means of identifying and diagnosing children with learning disabilities. A standardized battery of memory tests would be a great step toward this end. 


\section{REFERENCES}

Aaronson, D., Stimulus factors and listening strategies in aúditory memory: A theoretical analysis. Cognitive Psychology, 6, 108-132 (1974).

Aten, J. I., Auditory memory and auditory sequencing. In D. I. Rampp (Ed.), Proceedings of the Memphis State University's First Annual Symposium on Auditory Processing and Learning Disabilities. Las Vegas, Nevada (1972).

, and Davis, J., Disturbances in the perception of auditory sequence in children with minimal cerebral dysfunction. Journal of Speech and Hearing Research, $11,236-245(1968)$.

Baker, H., and Leland, B., Detroit Tests of Learning Aptitude. Indianapolis: Bobbs-Merrill (1959).

Berry, M. F., Language Disorders of Children: The Bases and Diagnoses. Englewood Cliffs, N. J.: Prentice-Hall (1969).

Chalfant, J. C., and Scheffelin, M. A., Central Processing Dysfunctions in Children: A Review of Research. Bethesda, Md.: U.S. Department of Health, Education Welfare (1969).

Drexler, H., "Application of Distinctive Feature Analysis to Articulation Therapy," lecture presented at Portland State University, Portland, Oregon, Winter 1974. (Mimeographed.)

Fudala, J., "Short Term Memory through Special Education Students," seminar presented at the Oregon-Washington Speech and Hearing Association Fall Conference, Portland, Oregon, October 10, 1975.

Hayes, J. R. M., Memory span for several vocabularies as a function of vocabulary size. In Quarterly Progress Report, Acoustics Iaboratory, Jan.-June, Cambridge, Mass.: Massachesettes Institute of Technology (1952).

Hays, W. L., Statistics for the Social Sciences. New York: Holt, Rinehart and Winston (1973). 
Hunt, H., Area I Coordinator, Portland Public School District \#l, Portland, Oregon. Personal correspondence, April 8, 1976.

Johnson, D. J., and Myklebust, H. R., Learning Disabilities: Educational Principles and Practices. New York: Grune and Stratton (1971).

Kirk, S., McCarthy, J., and Kirk, W., Illinois Test of Psycholinguistic Abilities. Champaign, Illinois: University of Illinois Press (1968).

Lasky, E. Z., Jay, B., and Hanz, M. L., "Interaction of Task Difficulty and Complexity of the Listening Environment on Children's Auditory Processing Skills," paper presented at the American Speech and Hearing Association Annual Convention, Detroit, Michigan, October 11$15,1973$.

McCarthy, J., and Kirk, S., Illinois Test of Psycholinguistic Abilities. Champaign, Illinois: University of Illinois Press (1963).

Aliyn and Bacon ( 1969 ).

Learning Disabilities. Boston:

and Olson J., "Validity Studies on the ITPA." Madison, Wisc.: University of Wisconsin (1964), cited by S. H. Lamb, "The Illinois Test of Psycholinguistic Abilities: Implications for Diagnosis and Remediation," in L. Tarnopol (Ed.), Learning Disabilities. Springfield, Ill.: Charles C. Thomas (1969).

Monsees, E. K., Temporal sequence and expressive language disorders. Exceptional Children, 35, 141-147 (1968).

Myklebust, H. R., "Childhood Aphasia: An Evolving Concept," in L. E. Travis (Ed.), Handbook of Speech Pathology and Audiology. New York: Appleton-Century-Crofts (1971a).

"Childhood Aphasia: Identification, Diagnosis, Remediation," in L. E. Travis (Ed.), Handbook of Speech Pathology and Audiology. New York: Appleton-CenturyCrofts (1971b).

Neisser, U., Cognitive Psychology. New York: AppletonCentury-Crofts (1966). 
Turaids, D., Wepman, J. M., and Morency, A., A perceptual test battery: Development and standardization. Elementary School Journal, 72, 351-361 (1972).

Zigmond, N. K., "Auditory Processes in Children with Learning Disabilities," in L. Tarnopol (Ed.), Learning Disabilities. Springfield, Ill.: Charles C. Thomas (1969). 
APPENDICES 
APPENDIX A

PARENT PERMISSION FORM

$$
\text { January 21, } 1976
$$

Dear Parent or Guardian:

I am a Portland State University graduate student doing a research project in Speech and Hearing Science. I have received permission from the Portland Public Schools to engage students in 2nd, 3rd, and 4th grade classes in Smith and Stephenson Schools as subjects in my study. The subjects will listen to tape recorded sequences of words and repeat the words back to me. This will take approximately 30 minutes for each child.

No names will be used in the written results of the study. The information obtained in the study may be made available to the classroom teachers involved and the school speech pathologist to aid them in their programming.

I am requesting permission for your child to participate in the project outlined above. Please send the signed form below with your child back to his/her teacher as soon as possible. Please take care to answer the questions on the form. Thank you very much.

Sincerely, Sandra I. Burford

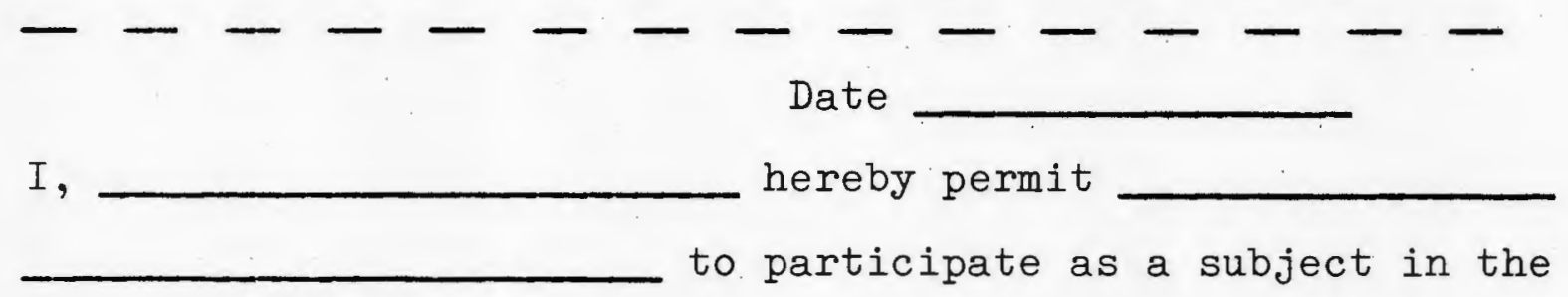
study conducted by Sandra Burford in Smith/Stephenson School.

* My child (has/has not) received remedial help in Speech/ Language.

* My child (has/has not) received remedial help in Reading. Signed 
APPENDIX B

\section{RESPONSE FORM}
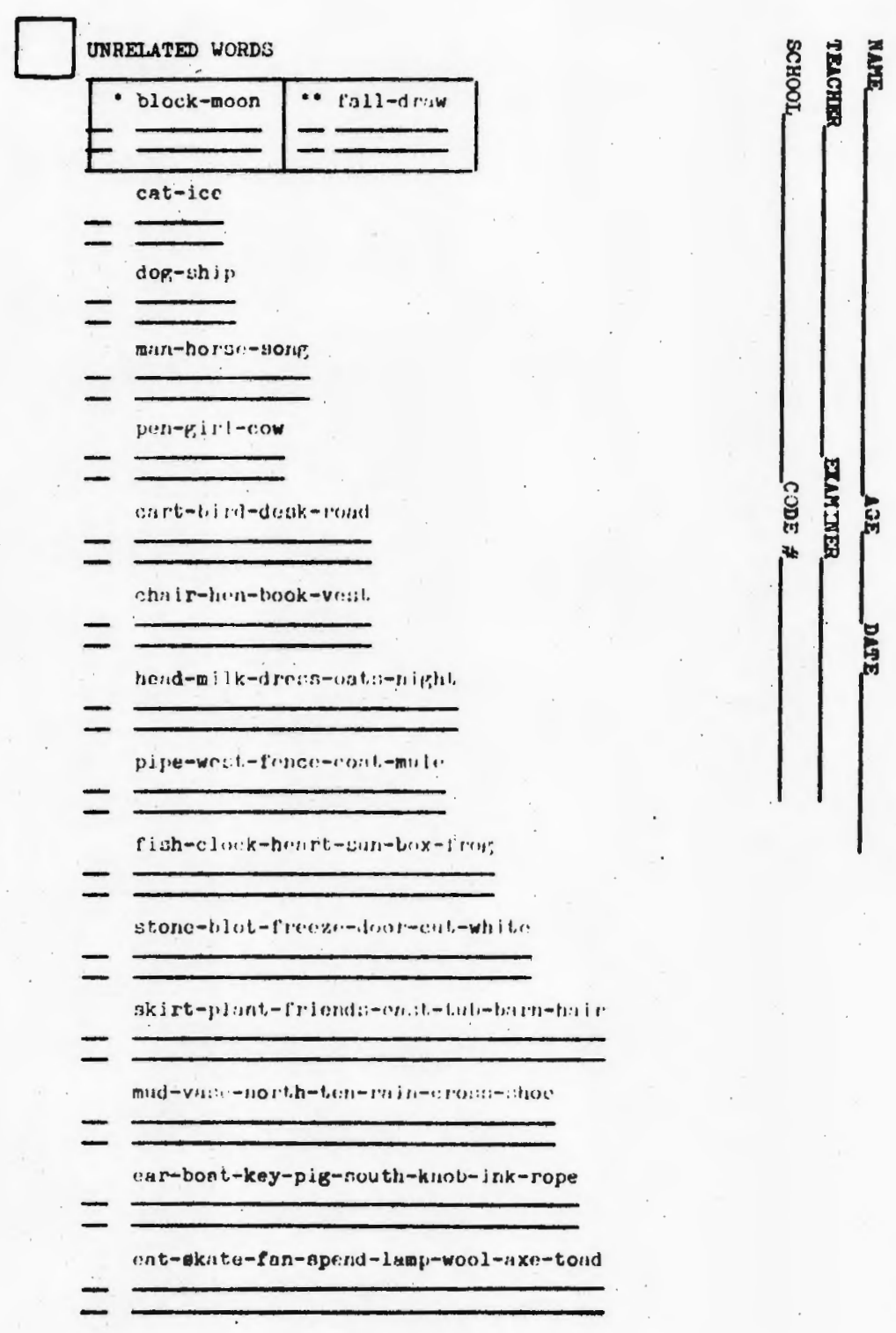


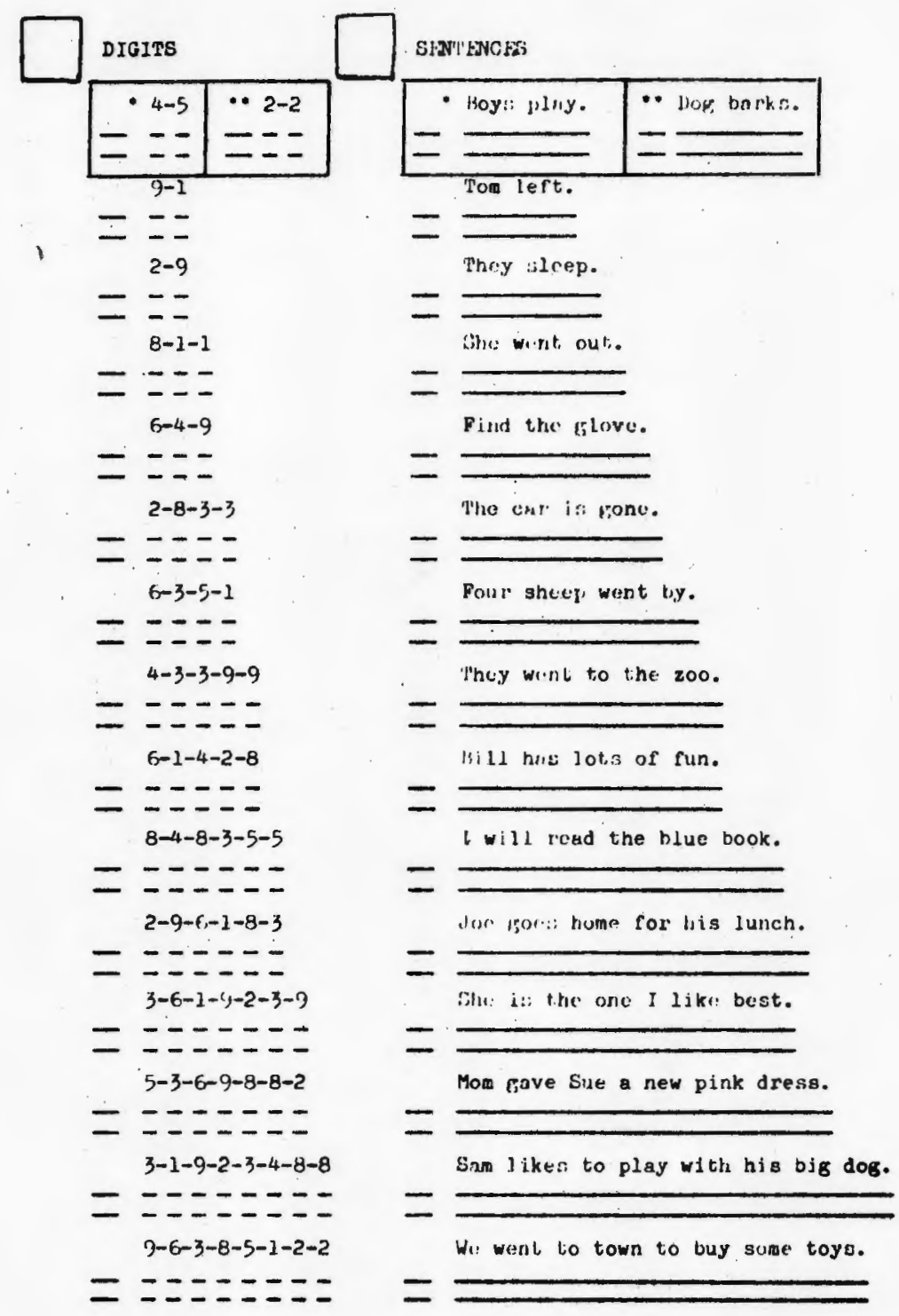


NOHSBSE WORDS

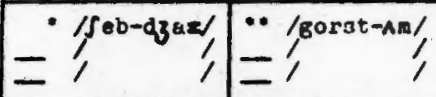

$=l^{\text {pid-tis? }}$

$=\%$

$=\%^{\text {pem-krrg-brzn/; }}$

$=2^{/ \operatorname{tar}-\operatorname{mov} s-\operatorname{sum} / /}$

$=1 /$ tur-ladz-wep-dit/,

$=3^{/+s-r a l-\rho o r-h u r /}$

$=1 /$ Jg-2lr-bog-at-rnz/,

$=1 /$ fodj-hev-nxi-nk-suz/,

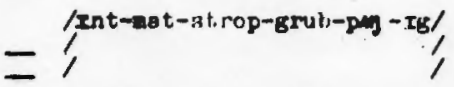

$=3^{1 \operatorname{lin}-t \ln -n i p-i z n-d j z d-k n z /,}$

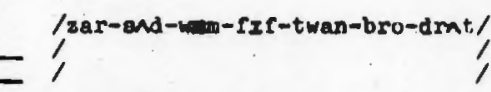

$=1 /$ /ro-dof-ra-2xk-arn-job-2up/,

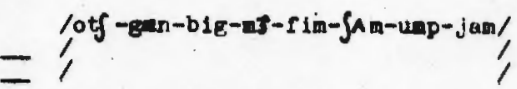

$=1 /$ trabi-8ab-nxgk-bam-imnp-m1f-leg-bup// 


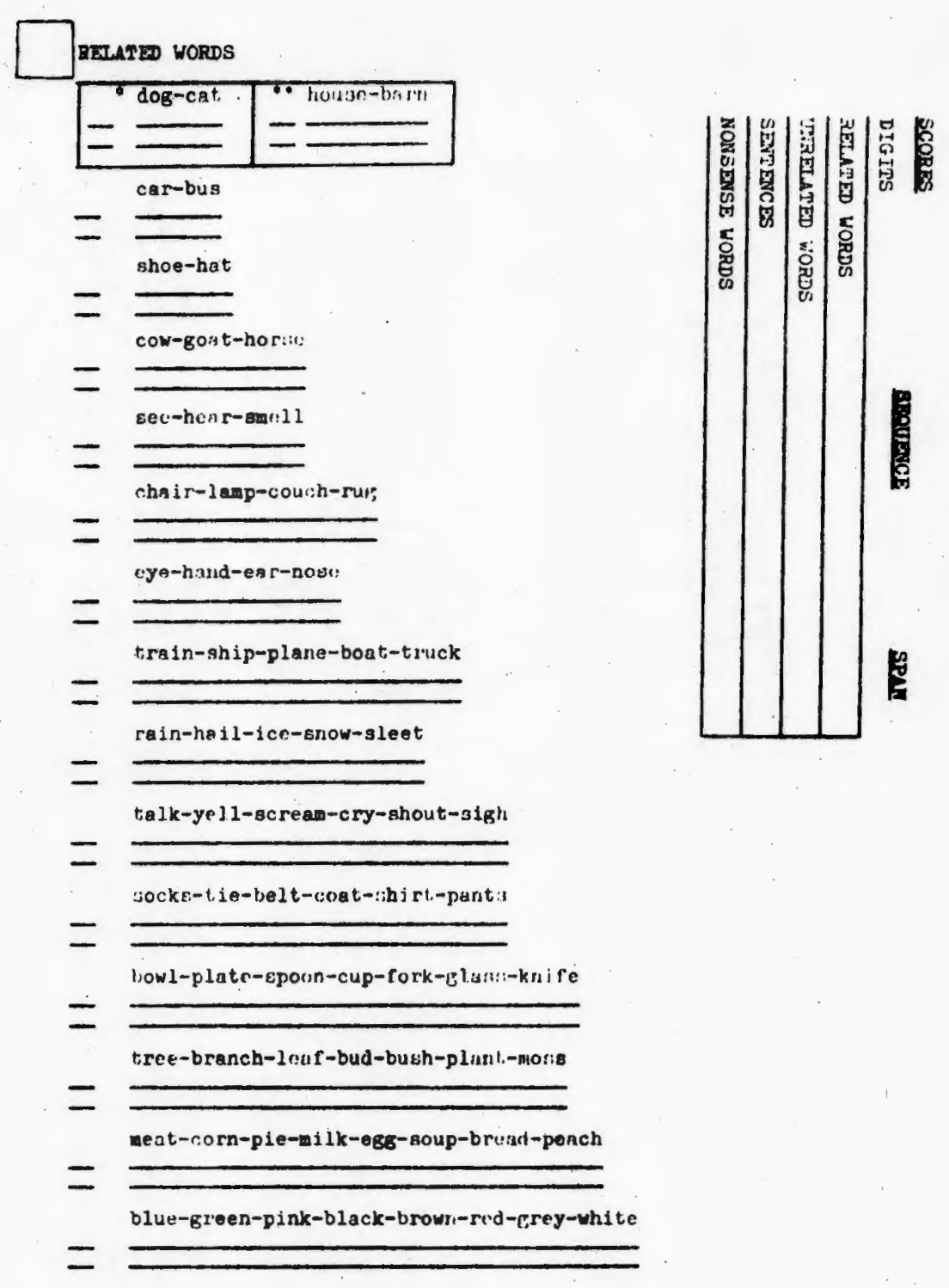




\section{APPENDIX C}

\section{SEVEN WORD DISCRIMINATION LIST}

Discriminations were made between the following seven pairs of words or nonsense words:
1. /su/
$\mid$ sum $\left.\right|^{+} \quad\left(\right.$ test item $4^{*}$ )
2. /rub/
/grub/ ${ }^{+}$(test item $9^{*}$ )
3. $/ \mathrm{V} \wedge \mathrm{I} /$
$/\left.\mathrm{vo}\right|^{+} \quad($ test item 12*)
4. /j^m/
$/\left.\mathrm{jam}\right|^{+}$(test item 13*)
5. move
moon ${ }^{+}$
(sample item $1^{* *}$ )
6. barn $^{+}$
burn
(test item 11**)
7. year
ear $^{+}$
(test item 13**)

+ Woras chosen by two trained listeners.

* Nonsense Wora subtest

* * Unrelated Word subtest 


\section{APPENDIX D}

TEST ORDER IIST

1. 54213

2. 42531

3. 34125

4. 43251

5. 21435

6. 51243

7. 41253

8. 34251

9. 42351

10. 43512

11. 43215

12. 14253

13. 25341

14. 41235

15. 13524
16. 41523

17. 32145

18. 35124

19. 51423

20. 12345

21. 45132

22. 21453

23. 42351

24. 31245

25. 13452

26. 54312

27. 41532

28. 51324

29. 24153

30. 32145
31. 41253

32. 51432

33. 42531

34. 42153

35. 51342

36. 31524

37. 41352

38. 54312

39. 31452

40. 13245

41. 54132

42. 45132

43. 31245

44. 34215

45. 14235 


\section{APPENDIX E \\ INSTRUMENTATION SPECIFICATIONS}

Sony Condenser Microphone Model C-37A

Frequency Response: 30-16,000 Hz within $5 \mathrm{~dB}$

Signal-To-Noise Ratio: better than $60 \mathrm{~dB}$ on a $1000 \mathrm{~Hz}$, 10 millibar sound

Unidirectional

Mike compensated for room characteristics

Sony Stereo Tapecorder Model TC 777-2 (half-track)

Frequency Response: 40-16,000 Hz $\pm 2 \mathrm{~dB}$ at $7-1 / 2$ ips. Signal-To-Noise Ratio: $50 \mathrm{~dB}$ or better

Wow \& Flutter: less than $0.1 \%$ at $7-1 / 2$ ips.

Ampex 406 Mastering Tape

Uniformity at $15 \mathrm{mil}$ wavelength in $\mathrm{dB}$ : within roll: \pm 0.25 between roll: \pm 1.0

Relative weighted noise level in $\mathrm{dB}: 0.0$

Resistivity Back-Coating (ohms/square): $0.5 \times 10^{6}$

Telex Series 235 CS-1 Reel to Cassette Duplicating System

Frequency Response: $30-10,000 \mathrm{~Hz} \pm 3 \mathrm{~dB}$ at $1-7 / 8$ ips.

Signal-To-Noise Ratio: within $3 \mathrm{~dB}$ of master tapes

Wow \& Flutter: $0.25 \%$ rms.

Crosstalk rejection: better than $45 \mathrm{~dB}$ at all frequencies

Distortion: less than $1 \% \mathrm{THD}$ at $1 \mathrm{KHz}$ at zero VU at $7-1 / 2$ ips.

TDK C-60Y Cassette Tapes

Signal-To-Noise Ratio: $-4.0 \mathrm{~dB}$

Print-through: minimum $53 \mathrm{~dB}$

Uniformity: at $333 \mathrm{~Hz}$, maximum: $1.0 \mathrm{~dB}$

at $8 \mathrm{KHz}$, maximum: $2.0 \mathrm{VU}$ 
Sony TC-95 A Cassette-Corder

Frequency Response: 50-10,000 Hz Signal-To-Noise Ratio: $45 \mathrm{~dB}$ or more 


\section{APPENDIX F}

DISTINCTIVE FEATURE GRID

RELEASES SYLLABLE

\begin{tabular}{|c|c|c|c|c|c|c|c|c|c|c|c|}
\hline VOWEL & $\mathrm{p}$ & $\mathrm{b}$ & $t$ & $\mathrm{~d}$ & $\mathrm{k}$ & g & $\mathrm{m}$ & $\mathrm{n}$ & W & $j$ & 1 \\
\hline NASAL & & & & & & & + & + & & & \\
\hline GIIDE & & & & & & & & & + & + & + \\
\hline FRICATIVE & & & & & & & & & & & \\
\hline STOP & + & + & + & + & + & + & & & & & \\
\hline VOICED & & + & & + & & + & + & + & + & + & + \\
\hline BIIABIAI & + & + & & & & & + & & + & & \\
\hline LABIO-DENT & & & & & & & & & & & \\
\hline LING-DENT & & & & & & & & & & & \\
\hline ALVEOLAR & & & + & + & & & & + & & & + \\
\hline POST-ALV. & & & & & & & & & & + & \\
\hline VELAR & & & & & + & + & & & & & \\
\hline GLOTTAL & & & & & & & & & & & \\
\hline
\end{tabular}

\begin{tabular}{|c|c|c|c|c|c|c|c|c|c|c|c|}
\hline VOWEL & $r$ & $f$ & $\mathrm{~V}$ & $\theta$ & $\gamma$ & $\mathrm{s}$ & $\mathrm{z}$ & S & $d z$ & $t$ & $\mathrm{~h}$ \\
\hline NASAL & & & & & & & & & & & \\
\hline GLIDE & + & & & & & & & & & & \\
\hline FRICATIVE & & + & + & + & + & + & + & + & + & + & + \\
\hline STOP & & & & & & & & & + & + & \\
\hline VOICED & + & & + & & + & & + & & + & & \\
\hline BILABIAI & & & & & & & & & & & \\
\hline IABIO-DENT & & + & + & & & & & & & & \\
\hline IING-DENT & & & & + & + & & & & & & \\
\hline AIVEOLAR & & & & & & + & $t$ & & & & \\
\hline POST-AIV. & + & & & & & & & + & + & + & \\
\hline VEIAR & & & & & & & & & & & \\
\hline GLOTTAL & & & & & & & & & & & + \\
\hline
\end{tabular}

SOURCE: H. Drexler, "Application of Distinctive

Feature Analysis to Articulation Therapy," lecture presented at Portland State University, Portland, Oregon, Winter, 1974. 
DISTINCTIVE FEATURE GRID

ARRESTS SYLLABLE

\begin{tabular}{|c|c|c|c|c|c|c|c|c|c|c|c|}
\hline & $p$ & $\mathrm{~b}$ & $t$ & d & $\mathrm{k}$ & $g$ & m & $n$ & $\eta$ & 1 & 3 \\
\hline VOWEL & & & & & & & & & & + & + \\
\hline NASAI & & & & & & & + & + & + & & \\
\hline GLIDE & & & & & & & & & & & \\
\hline \multicolumn{12}{|l|}{ FRICATIVE } \\
\hline STOP & $t$ & $t$ & + & + & + & $t$ & & & & & \\
\hline VOICED & & + & & + & & + & + & + & + & + & + \\
\hline BIIABIAI & + & + & & & & & + & & & & \\
\hline \multicolumn{12}{|l|}{ IABIO-DENT } \\
\hline \multicolumn{12}{|l|}{ IING-DENT } \\
\hline ALVEOLAR & & & + & + & & & & + & & + & \\
\hline POST-ALV. & & & & & & & & & & & + \\
\hline VEIAR & & & & & + & + & & & + & & \\
\hline GLOTMAL & & & & & & & & & & & \\
\hline
\end{tabular}

\begin{tabular}{|c|c|c|c|c|c|c|c|c|c|c|c|}
\hline VOWEI & $f$ & V & $\theta$ & $y^{2}$ & $s$ & z & $\int$ & 3 & $\operatorname{tg}$ & $d z$ & \\
\hline \multicolumn{12}{|l|}{ NASAI } \\
\hline \multicolumn{12}{|l|}{ GLIDE } \\
\hline FRICATIVE & + & + & + & + & + & + & + & + & + & + & \\
\hline STOP & & & & & & & & & + & + & \\
\hline VOICED & & + & & + & & + & & + & & + & \\
\hline \multicolumn{12}{|l|}{ BIIABIAI } \\
\hline IABIO-DENT & + & + & & & & & & & & & \\
\hline LING-DENT & & & + & + & & & & & & & \\
\hline ALVEOLAR & & & & & + & + & & & & & \\
\hline POST-ALV. & & & & & & & + & + & + & + & \\
\hline \multicolumn{12}{|l|}{ VEI,AR } \\
\hline GLOTTAL & & & & & & & & & & & \\
\hline
\end{tabular}

$$
\text { SOURCE: H. Drexler, "Application of Distinctive }
$$

Feature Analysis to Articulation Therapy," lecture presented at Portland State. University, Portland, Oregon, Winter, 1974. 